\title{
RESÍDUOS DE CASAS DE FARINHA DO AGRESTE ALAGOANO: PERSPECTIVAS DE UTILIZAÇÃO
}

\author{
S. de O. Souza ${ }^{1 *}$, A. P. B. da Silva ${ }^{1}$, R. M. da Silva ${ }^{2}$, L. C. de Oliveira ${ }^{3}$, D. Goveia ${ }^{4}$, W. G. \\ Botero $^{2}$ \\ ${ }^{1}$ UFAL - Univ Federal de Alagoas, Câmpus de Maceió, Maceió, Alagoas, Brasil \\ ${ }^{2}$ UFAL - Univ Federal de Alagoas, Câmpus de Arapiraca, Arapiraca, Alagoas, Brasil \\ ${ }^{3}$ UFSCAR - Univ Federal de São Carlos, Câmpus de Sorocaba, Sorocaba, São Paulo, Brasil \\ ${ }^{4}$ UNESP - Univ Estadual Paulista, Câmpus Itapeva, Itapeva, São Paulo, Brasil
}

\section{RESUMO}

O Brasil se destaca no cenário mundial como produtor agrícola, dentre os diversos tipos de cultivo, a mandioca é considerada um dos principais, devido o aproveitamento de quase todas as partes dessa espécie vegetal. É um produto tanto de uso alimentar para o ser humano quanto para animais. No entanto, um problema que vem sendo observado é a elevada produção de resíduos oriundos do processamento da mandioca, gerando danos ao meio ambiente e a sociedade, inclusive devido sua toxicidade. Desses resíduos merecem destaque a casca da mandioca e a manipueira, líquido de cor amarelo-claro resultante da prensagem da massa da mandioca. Neste trabalho foi comprovado que esses subprodutos apresentam teores consideráveis para macro, micronutrientes e matéria orgânica, portanto podem apresentar diversas aplicações, dentre elas o uso para complementação na ração de animais e principalmente na aplicação no solo como fertilizante, em diversas culturas, gerando renda, diminuindo custos e consequentemente minimizando os danos que vem trazendo ao meio ambiente.

Palavras-chave: Resíduos da mandioca; Fertilizante; Ração animal.

\section{WASTE OF FLOUR HOUSES OF ALAGOAS STATE: USE AND PERSPECTIVES}

\begin{abstract}
The Brazil is one of the largest agricultural producers in the world, among the various types of farming, cassava is considered one of the main, because the use of almost all parts of this plant. It is a food grade product both for humans and for animals. However, it is observed in this case a high production of waste that can generate damage to the environment and society, including because of its toxicity. Such waste should be highlighted the cassava peel and Manipueira. Manipueira is a liquid light yellow color resulting from the pressing of the mass of cassava. This work demonstrated that these sub-products have considerable levels for macro, micronutrients and organic matter, and may present several applications, among them the use to supplement in animal feed and especially in soil application as fertilizer, in different cultures, generating income, thus reducing costs and minimizing damage to the environment has been drawing.
\end{abstract}

Keywords: Cassava Waste; Fertilizer; Animal feed.

\footnotetext{
*sheniaquimica@gmail.com
} 


\section{INTRODUÇÃO}

O Brasil, destaca-se no cenário mundial como produtor de mandioca (Manihot esculenta Crantz). Dessa raiz, são comercializados mais de 100 itens que mostram o papel que esse produto exerce na economia do país, principalmente nas regiões Norte e Nordeste (CORDEIRO, 2006; LAMAISON, 2009).

Do processamento da mandioca são gerados, além dos produtos de consumo direto para a população e para os animais, resíduos que acabam gerando problemas ambientais, destacando-se a manipueira e a casca da mandioca. Esses resíduos são descartados no ambiente ou destinados a complementação animal, entretanto são escassos dados referentes aos níveis de contaminantes, nutrientes e outras informações essenciais para a aplicação desses resíduos no ambiente, evitando assim a contaminação ambiental.

A manipueira, líquido de cor amarelo-claro, em tupi-guarani quer dizer "o que brota da mandioca" (CARDOSO JÚNIOR et al., 2005), é um dos resíduos gerados no processamento da mandioca, através de uma operação de compressão (MÉLO et al., 2005). Rica em açúcares, amidos, proteínas, linamarina, sais, cianeto e outras substâncias (DUARTE et al., 2012), sua composição química sustenta a sua potencialidade como nutriente, haja vista seu elevado teor de potássio, magnésio, fósforo, cálcio, enxofre, ferro e micronutrientes em geral (CORDEIRO, 2006).

Estudos comprovam o uso da manipueira, tanto do ponto de vista agrícola, como fonte de nutrientes às plantas, podendo ser utilizada como adubação agrícola, produção de biogás, pesticida e nematicida e principalmente como na adsorção de metais potencialmente tóxicos (MPT) (SODRÉ et al., 2012), mas é na complementação na alimentação animal, que tem sido o novo direcionamento da utilização desse resíduo.

Entretanto, uma limitação a ser enfrentada é a presença do glicosídio linamarina potencialmente hidrolisável a ácido cianídrico. Este glicosídeo combinase com a hemoglobina do sangue, sendo um potente inibidor da cadeia respiratória (CARDOSO JÚNIOR et al., 2005; DUARTE et al., 2012; NASU et al., 2010; SANTOS et al., 2010). A disposição desse efluente, energeticamente não esgotado e que apresenta uma alta toxicidade, em corpos d'água, acarreta prejuízos de ordem ambiental, uma vez que diminui a disponibilidade aquática de oxigênio (WOSIACKI \& CEREDA, 2002).

A casca se destaca pelo seu uso como ração animal. Este resíduo sólido é obtido no processo de descascamento da mandioca para a produção da farinha, é a película que envolve a camada protetora da raiz denominada de entrecasca (BRASIL, 1995).

A alimentação animal no Nordeste brasileiro muitas vezes é vista como um desafio. A presença de uma estação seca prolongada durante o ano faz com que os agricultores e criadores busquem fontes alternativas para suprir a carência alimentar de seus rebanhos, mesmo que a base alimentar ainda seja exclusivamente composta por pastagens, quer em áreas de campo naturais ou em pastagens cultivadas. Atualmente observa-se que a utilização de resíduos da agricultura tem-se tornado um forte aliado para ajudar a reduzir os custos da produção do rebanho (FERREIRA et al., 2007).

Nesse sentido, a utilização destes resíduos seja na complementação animal ou aplicação agrícola, se mostra uma alternativa interessante e promissora. Entretanto é necessário conhecer os teores de nutrientes, matéria orgânica e contaminantes presentes nesses resíduos antes de sua aplicação, evitando desperdícios e aplicação inadequada e ao mesmo tempo contribuir para diminuir o lançamento indiscriminado no ambiente que pode ocasionar desequilíbrios ambientais.

Assim, este trabalho teve por objetivo avaliar as características em relação aos teores de matéria orgânica e 
nutrientes presentes nos resíduos gerados nas casas de farinha do agreste alagoano (manipueira e cascas de mandioca) para uma possível aplicação na agricultura e complementação da alimentação animal, contribuindo para o melhor entendimento

\section{MATERIAIS E MÉTODOS}

Todos os reagentes que foram utilizados para preparo de soluções padrões, limpeza e descontaminação das das características destes resíduos nesta região e consequentemente estimular o uso dos mesmos visando diminuir os impactos ambientais que estão associados a sua disposição inadequada no ambiente.

vidrarias são de grau e pureza analítica. Todas as soluções foram preparadas com água purificada em sistema Milli-Q.

\section{Coleta e preparo de amostras de cascas de mandioca e manipueira}

A coleta de amostras de manipueira e casca de mandioca foram realizadas em Novembro/Dezembro de 2013 em uma casa de farinha localizada no município de Coité do Nóia no Agreste Alagoano. A casa de farinha onde as amostras foram coletadas processa cerca de $75.000 \mathrm{~kg}$ de mandioca/mês, gerando $30.000 \mathrm{~L}$ de manipueira e $15.000 \mathrm{~kg}$ de casca de mandioca por mês de trabalho.

Foram coletados $2 \mathrm{~L}$ de manipueira, condicionados em recipiente de plástico e mantidos sob refrigeração, e cerca de $1 \mathrm{~kg}$ de cascas de mandioca e condicionadas em sacos plásticos.

No laboratório foi feito o preparo das amostras. Para a amostra de manipueira foram utilizadas alíquotas de $20 \mathrm{~mL}$ desse resíduo, adicionados a mesma $10 \mathrm{~mL}$ de ácido nítrico concentrado, $5 \mathrm{~mL}$ de peróxido de hidrogênio $30 \% \quad(\mathrm{v} / \mathrm{v})$ e submetidas a aquecimento a $110{ }^{\circ} \mathrm{C}$. Após a digestão, o extrato obtido foi transferido para um balão volumétrico de $50 \mathrm{~mL}$, o qual teve seu volume completado (ROSA et al., 2007).

As amostras de casca de mandioca foram inicialmente submetidas ao aquecimento em estufa, a $60{ }^{\circ} \mathrm{C}$. Após resfriamento, macerou-se uma porção de cascas, e cerca de 2,00 g dessa amostra foi utilizada por replicata. Para a digestão desse resíduo foram necessários utilizar 20 $\mathrm{mL}$ de ácido nítrico concentrado e $5 \mathrm{~mL}$ de solução de peróxido de hidrogênio a $30 \%$ (v/v), aquecido posteriormente a $110{ }^{\circ} \mathrm{C}$, conforme procedimento realizado com a amostra de manipueira. Todo o procedimento de preparo das amostras foi realizado em triplicata.

\section{Determinações de macro, micronutrientes em amostras de manipueira e casca de mandioca}

Os macro e micronutrientes foram induzido (ICP-OES), utilizando-se determinados por espectrometria de emissão atômica com plasma de argônio soluções padrão mista para curva de calibração (SANTOS, 2003).

\section{Determinação do teor de matéria orgânica de casca de mandioca e manipueira}

A determinação do teor de matéria orgânica (MO) foi realizada em mufla, por calcinação a $750{ }^{\circ} \mathrm{C}$, durante $4 \mathrm{~h}$, de acordo

\section{RESULTADOS E DISCUSSÃO}

Dados referentes aos teores de matéria orgânica e nutrientes são essenciais quando se avalia a possível aplicação de resíduos, seja para uso na complementação com o procedimento recomendado por ROSA (2001).

na alimentação animal ou para aplicação na agricultura. Na Tabela 1 estão descritos os teores de matéria orgânica determinados nas amostras de casca de mandioca e 
manipueira coletados no agreste alagoano e

de diferentes matrizes citadas na literatura.

Tabela 1. Teores de matéria orgânica nas amostras das cascas de mandioca e manipueira coletadas no agreste alagoano e de dados da literatura.

\begin{tabular}{ccl}
\hline Amostra & Teor de MO\% & Referência \\
\hline Casca de mandioca & $95,73 \pm 2,31$ & Este trabalho \\
Manipueira & $78,45 \pm 1,22$ & Este trabalho \\
Casca de mandioca & 92,01 & FERREIRA et al., 2007 \\
Massa de mandioca & 97,93 & FERREIRA et al., 2007 \\
LETA & 20,5 & BOTERO et al., 2009 \\
Jaboticabal-SP & & BOTERO et al., 2009 \\
LETA & 68,9 & \\
Manaus - AM & & \\
\hline
\end{tabular}

Os resultados da Tabela 1 mostram os elevados teores de matéria orgânica presentes nas amostras de cascas de mandioca e manipueira, os mesmos ainda se apresentam superiores aos teores de matéria orgânica encontrados nos resíduos denominados lodos das estações de tratamento de água (LETA) Jaboticabal SP e Manaus - AM.

$\mathrm{Na}$ alimentação animal, a mandioca pode ser fornecida nas mais variadas formas: raízes frescas, restos culturais e subprodutos sólidos. Observa-se que a mandioca e seus subprodutos representam excelentes fontes energéticas para a alimentação de ruminantes, principalmente devido ao balanço nos preços deste produto (RODRIGUEZ et al., s/d).

A mandioca apesar de possuir grande potencial como alimento energético para bovinos é pouco utilizada como componente na produção de rações. Além da utilização das raspas de mandioca, existem vários resíduos oriundos da industrialização que também podem ser utilizados na alimentação animal (SOUZA \& BOIN, 2002).

Segundo DEL BIANCHI \& CEREDA (1999), dos resíduos sólidos, a casca representa a maior porcentagem gerada em massa, 15 a $20 \%$ em peso úmido, 10 a $15 \%$ em peso seco, com cerca de $66,6 \%$ de amido. Ao compararem cascas de mandioca e milho como diferentes fontes energéticas, observou-se que rações com casca de mandioca apresentaram maior digestibilidade da matéria seca (MS), matéria orgânica (MO), proteína bruta $(\mathrm{PB})$ e amido, corroborando com os elevados teores de matéria orgânica apresentados na Tabela 1 (MARTINS et al., 2000).

Além dos teores de matéria orgânica, é interessante determinar os teores de nutrientes presentes nos resíduos. $\mathrm{Na}$ Tabela 2 está descrito os teores de macro e micronutrientes determinados nas amostras manipueira e casca de mandioca do agreste alagoano. 
Tabela 2. Teores de macro e micronutrientes em amostras de manipueira e casca de mandioca

\begin{tabular}{|c|c|c|c|}
\hline Parâmetros & $\begin{array}{c}\text { Manipueira } \\
\left(\mathrm{mg} \mathrm{L}^{-1}\right) \\
\text { (Este trabalho) } \\
\end{array}$ & $\begin{array}{c}\text { Casca de mandioca } \\
\left(\mathrm{mg} \mathrm{kg}^{-1}\right) \\
\text { (Este trabalho) } \\
\end{array}$ & $\begin{array}{l}\text { Extrato da casca do fruto } \\
\text { do cacaueiro }\left(\mathrm{mg} \mathrm{kg}^{-1}\right) \\
\text { (SODRÉ et al., 2012) }\end{array}$ \\
\hline $\mathrm{Cu}^{2+}$ & $0,74 \pm 0,02$ & $3,24 \pm 0,02$ & $74,00 \pm 30,5$ \\
\hline $\mathrm{Fe}^{2+}$ & $21,42 \pm 0,04$ & $12,90 \pm 0,02$ & $888,00 \pm 406,8$ \\
\hline $\mathbf{Z n}^{2+}$ & $5,21 \pm 0,02$ & $4,98 \pm 0,02$ & $1.690,00 \pm 825,2$ \\
\hline $\mathrm{Mn}^{2+}$ & $2,28 \pm 0,01$ & $3,67 \pm 0,02$ & $234,00 \pm 98,6$ \\
\hline $\mathrm{Cd}^{2+}$ & $0,045 \pm 0,01$ & $0,17 \pm 0,01$ & -- \\
\hline $\mathrm{Ni}^{2+}$ & $0,98 \pm 0,02$ & $7,98 \pm 0,02$ & --- \\
\hline $\mathbf{P}$ & $390,00 \pm 0,07$ & $625,00 \pm 0,30$ & $2.600,00 \pm 50,00$ \\
\hline $\mathrm{Ca}^{2+}$ & $245,00 \pm 0,08$ & $7.000,00 \pm 5,0$ & $13.100,00 \pm 4.500,00$ \\
\hline $\mathrm{Mg}^{2+}$ & $222,00 \pm 0,04$ & $790,00 \pm 1,50$ & $14.000,00 \pm 5.000,00$ \\
\hline $\mathrm{Na}^{+}$ & $199,50 \pm 0,11$ & $1.589,00 \pm 2,00$ & --- \\
\hline $\mathbf{K}^{+}$ & $779,12 \pm 0,22$ & $14.700,00 \pm 7,00$ & $145.900,00 \pm 58.200,00$ \\
\hline
\end{tabular}

Pela Tabela 2 observa-se que os resíduos são compostos essencialmente por nutrientes como fósforo, potássio, cálcio, magnésio, enxofre, zinco, manganês, ferro, cobre e sódio, porém para a composição da casca de mandioca é observado valores superiores se comparados aos da manipueira, isso se deve provavelmente porque na manipueira esses teores de nutrientes estão diluídos na forma de um resíduo líquido, já que o mesmo é representado por uma considerável quantidade de água em sua constituição.

Esses resultados listados corroboram com aqueles determinados por NASU et al. (2010) para manipueira caseira do Oeste do Paraná, portanto verifica-se a proposta de utilização da manipueira como complemento para alimentação animal e na agricultura como biofertilizante.

No entanto, as aplicações desse resíduo são possíveis após encontrar meios para solucionar o problema dos elevadores teores de cianeto presentes nessa água residual, SOUZA e colaboradores (2014) realizaram estudos propondo a redução de cianeto nesse resíduo para assim dar-se seguimento ao seu uso sem gerar danos ao meio ambiente. Estudos em função do tempo e da temperatura para verificar a liberação de cianeto pela manipueira foram úteis, pois trouxeram informações a respeito do tempo mínimo exigido para que a concentração de cianeto na manipueira atingisse um nível seguro, assim garantindo uma diminuição ou uma prevenção dos danos ambientais resultante do lançamento deste resíduo no ambiente.

SOUZA et al. (2014) também avaliou que a manipueira resultante da raiz coletada no período chuvoso (maio-agosto) se apresente mais adequada para aplicação, pois contem maior teor de nutrientes se comparado a manipueira resultante de uma raiz coletada no período de seca no semiárido nordestino.

Comparando ainda esses resultados com os apresentados por SODRÉ et al. (2012), percebe-se que dependendo da forma do processamento das raízes, a água residual, produzida a partir do processamento da farinha de mandioca, pode apresentar com variadas concentrações. Dos resultados propostos por BARBOSA et al. (2012), dos nutrientes estudados, apenas fósforo e ferro apresentaram valores inferiores se comparados aos obtidos nas manipueiras extraídas da mandioca do semiárido alagoano, portanto é sugerido o aproveitamento desse resíduo líquido na alimentação de ruminantes, suínos, ovinos, dentre outras espécies animais por possuírem valores razoáveis para os nutrientes apresentados.

De acordo com FIORETTO (2001), existe uma predominância de potássio entre os constituintes minerais da manipueira, bem como níveis significativos de fósforo, o que possibilita 
a utilização deste resíduo como fertilizante, mesmo embora o fósforo seja um macronutriente menos exigido pelas espécies vegetais, assim sugere-se o uso agrícola dado os valores apreciáveis de nutrientes, gerando um melhoramento das propriedades químicas do solo.

Os teores de macro e micronutrientes presentes na casca da mandioca apresentam valores consideráveis, se comparado com outros resíduos, LOURENÇO e colaboradores (2013) mostraram a importância do uso da cama de aves como fertilizante de solos destinados ao plantio agrícola de feijoeiro. Os autores indicam o uso desse resíduo sólido pois o mesmo apresenta uma expressiva quantidade de nutrientes, tais como $\mathrm{K}$ e $\mathrm{P}$, assim conforme determinado na casca da mandioca. Além dessa aplicação, os consideráveis valores para cálcio e fósforo devem também ser destacados uma vez que as rações normalmente recebem acréscimo de fontes desses minerais (MACHADO \& COSTA, 2010).

Os valores para potássio e fósforo listados na Tabela 2 indicam o uso desse resíduo para adubação do solo com fins agrícolas. Estudos feitos por MANTOVANI e colaboradores (2004) mostraram que o uso do resíduo da indústria processadora de goiaba como fertilizante apresentou resultados satisfatórios, onde o aumento de $\mathrm{K}$ e $\mathrm{P}$ no solo foram pontos positivos destacados, confirmando que resíduos sólidos de origem vegetal ricos em $\mathrm{K}$ e $\mathrm{P}$ podem ser utilizados no melhoramento de solos destinados a agricultura.

É necessário destacar que na casa de farinha onde as amostras utilizadas neste trabalho foram coletadas, as cascas de mandioca são descartadas no ambiente ou

\section{CONCLUSÕES}

$\mathrm{Na}$ nutrição animal ou na aplicação agrícola, o uso de resíduos é apresentado como uma ferramenta interessante para se obter respostas positivas da eficiência alimentar, da redução de custos na pecuária são trituradas e utilizadas como complemento na alimentação animal. Entretanto há poucas informações na literatura quanto aos valores nutricionais presente neste subproduto, mas diversos estudos já estão presentes visando o uso de resíduos como complemento nutricional para diversos tipos de rebanhos, é o que se observa no trabalho devolvido por PELIZER e colaboradores (2007) em que utilizam resíduos agroindustriais para $o$ enriquecimento da ração animal apresentando paralelamente uma redução do impacto ambiental.

MENEZES et al. (2004) afirmam que esse resíduo sólido é um subproduto com valor nutritivo semelhante ao do milho. FERREIRA et al. (2007) afirmam que o valor energético do alimento não está na dependência apenas das quantidades dos diversos nutrientes em sua composição, mas, sobretudo, das frações desses nutrientes que o animal possa ingerir, digerir e utilizar. Para se ter uma ideia, ABRAHÃO e seus colaboradores (2005) afirmam que a casca de mandioca é um resíduo com baixa quantidade de proteína e grande quantidade de fibra e energia, sendo usado principalmente na alimentação de animais para engorda.

Estudos realizados por FARIA e colaboradores (2011) indicam o uso da casca da mandioca como um alimento alternativo, porém é ressaltado que este seja associado a técnicas de processamento que melhorem sua conservação ou seu aproveitamento nutricional.

$\mathrm{O}$ uso da casca como biofertilizante tem-se tornado uma alternativa viável para o agricultor, passando a aproveitar esse resíduo em suas plantações, que ora estava trazendo transtornos ambientais, gerando mal cheiro e acúmulo de insetos.

e na agricultura e da minimização de impactos ambientais. Gerar renda, diminuir custos, reduzir o acúmulo de subprodutos que poderiam trazer problemas para a sociedade e levando-os a 
serem geradores de riquezas são metas que se pretende atingir ao fornecer um destino útil aos resíduos gerados no processamento da farinha de mandioca.

Desta forma, os resultados obtidos comprovaram a utilização desses subprodutos da mandioca tanto como suporte para a agricultura como para a complementação na alimentação de animais.

\section{AGRADECIMENTOS}

Os autores agradecem a UFAL, APL da mandioca e ao CNPQ pelo apoio financeiro prestado.

\section{REFERÊNCIAS}

ABRAHÃO, J.J.S.; PRADO, I.N.; PEROTTO, D.; MOLLETA, José Luiz. Características de carcaças e da carne de tourinhos submetidos a dietas com diferentes níveis de substituição do milho por resíduo úmido da extração da fécula de mandioca. Revista Brasileira de Zootecnia, v.34, n.5, p.1640-1650, 2005.

BARBOSA, R. J.; SILVA, H. O.; RONER, M. N. B.; TEIXEIRA, S. G.; SOARES, C.; SANTOS, G. B. Desempenho de suínos alimentados com diferentes níveis de manipueira. PorkExpo, anais do VI Fórum Internacional de suinocultura. P. $17-18$. Curitiba - PR. 2012.

BOTERO, Wander Gustavo; SANTOS, Ademir; OLIVEIRA, Luciana Camargo; ROCHA, Julio Cesar. Caracterização de lodo gerado em estações de tratamento de água: perspectivas de aplicação agrícola. Química nova, v. 32, n. 8, p. 2018-2022. 2009

BRASIL. Ministério da Agricultura, Pecuária e Abastecimento. Secretaria da Agricultura, do Abastecimento e Reforma Agrária (MAPA). Portaria n ${ }^{\circ}$ 554, de 30 de agosto de 1995. Norma de identidade, qualidade, apresentação, embalagem, armazenamento e transporte da farinha de mandioca. Diário Oficial da República Federativa do Brasil, Brasília, DF, 01 set. 1995. Seção1. Disponível em:<http://www.cidasc.sc.gov.br/classifica cao/files/2012/08/Mandioca5543.htm.

Acesso em: 24 jan. 2015.

CARDOSO JÚNIOR, Nelson dos Santos; VIANA, A. E. S.; MATSUMOTO, S. N.; SEDIYAMA, T.; AMARAL, C. L. F.;
PIRES, A. J. V.; RAMOS, P. A. S. Efeito do nitrogênio sobre o teor de ácido cianídrico em plantas de mandioca. Acta Science Agronomy, v. 27, n. 4, p. 603-610, Out./Dez., Maringá. 2005.

CORDEIRO, Gustavo Quarezemin. Tratamento de manipueira em reator anaeróbio compartimentado. Dissertação (Mestrado), Instituto de Biociências, Letras e Ciências Exatas, Universidade Estadual Paulista Júlio de Mesquita Filho. São José do Rio Preto, 2006. Disponível em: <http://www.athena.biblioteca.unesp.br /exlibris/bd/brp/33004153070P3/2006/cord eiro_gq_me_sjrp.pdf $>$. Acesso em 24 janeiro de 2015.

DEL BIANCHI, V.L.; CEREDA, M.P. Balanço de massa de uma fábrica de mandioca de médio porte do Estado de São Paulo. Energia na Agricultura, v. 14, p. 3448. 1999

DUARTE, Ana Maria de S; SILVA, Ênio F. de F; ROLIM; Mário M; FERREIRA, Rafael F. de A. e L; MALHEIROS, Samuel M. M.; ALBUQUERQUE, Francimar da S. Uso de diferentes doses de manipueira na cultura da alface em substituição à adubação mineral. Revista Brasileira de Engenharia Agrícola e Ambiental, Campina Grande, v.16, n.3, p.262-267, 2012.

FARIA, Peter Bitencourt; SILVA, Jeovane Nascimento; RODRIGUES, Alisson Queiroz; TEIXEIRA, Priscilla Dutra; MELO, Leandra Queiroz; COSTA, Suely de Fátima; ROCHA, Maira Freitas Marques; PEREIRA, Alcilene de Abreu Pereira . Processamento da casca de 
mandioca na alimentação de ovinos: desempenho, características de carcaça, morfologia ruminal e eficiência econômica. Revista Brasileira de Zootecnia. V.40, n.12, p.2929-2937. Dez., 2011.

FERREIRA, Geane Dias Gonçalves; OLIVEIRA, Ronaldo Lopes; CARDOSO, Elyzabeth cruz; MAGALHÃES, André Luiz Rodrigues; BRITO, Elieldo Lameira. Valor Nutritivo de Co-produtos da mandioca. Rev. Bras. Saúde Prod. An. v.8, n.4, p. 364-374, Out/Dez, 2007.

FIORETTO, R. A. Manejo, uso e tratamento de subprodutos da industrialização da mandioca. São Paulo: Fundação Cargill, 2001.

LAMAISON, Franciele do CARMO. Aplicação da água residuária do processamento da mandioca como substrato para a produção de hidrogênio por processo fermentativo. Dissertação (Mestrado), Universidade Federal de Santa Catarina. Florianópolis, 2009. Disponível em:<www.pgeal.ufsc.br/files/2011/01/Diss ertação-Franciele-Laimason.pdf $>$. Acesso em: 24 janeiro de 2015.

LOURENÇO, Késia Silva; CORRÊA, Juliano Corulli; ERNANI, Paulo Roberto; LOPES, Letícia dos Santos; NICOLOSO, Rodrigo da Silveira. Crescimento e absorção de nutrientes pelo feijoeiro adubado com cama de aves e fertilizantes minerais. Revista Brasileira de Ciências do Solo, n. 37, p. 462-471, 2013.

MACHADO, Luiz Carlos; COSTA, Daviane Martinele. Qualidade do milho para utilização na

alimentação animal. III Semana de Ciência e Tecnologia do IFMG campus Bambuí III Jornada Científica. MG, Out., 2010.

MANTOVANI, José Ricardo; CORRÊA, Márcio Cléber de Medeiros; CRUZ, Mara Cristina Pessoa; FERREIRA, Manoel Evaristo; NATALE, William. Uso fertilizante de resíduo da indústria processadora de goiabas. Revista Brasileira de Fruticultura. Jaboticabal, v. 26, n.2, Ago., 2004.
MARTINS, A. S.; PRADO, I. N.; ZEOULA, L. M.; BRANCO, A. F.; NASCIMENTO, W. G. Digestibilidade aparente de dietas contendo milho ou casca de mandioca como fonte energética $\mathrm{e}$ farelo de algodão ou levedura como fonte proteica em novilhas. Revista da Sociedade Brasileira de Zootecnia, v. 29, n. 1, p. 269. 2000

MÉLO, Ralini Ferreira; FERREIRA, Paulo A.; RUIZ, Hugo A.; MATOS, Antônio Teixeira; OLIVEIRA, Lindomário Barros. Alterações físicas e químicas em três solos tratados com água residuária de mandioca. Irriga, Botucatu, v. 10, n. 4, p. 383-392, Nov./Dez., 2005.

MENEZES, Marcos Paulo Carrera; RIBEIRO, Maria Norma; COSTA, Roberto Germano; MEDEIROS; Ariosvaldo Nunes. Substituição do milho pela casca de mandioca (Manihot esculenta Crantz) em rações completas para caprinos: consumo, digestibilidade de nutrientes e ganho de peso. Revista Brasileira de Zootecnia, v.33, n.3, p.729737, 2004.

NASU, Érica G. C.; PIRES, Ely; FORMENTINI, Heloísa M.; FURLANETTO, Cleber. Efeito de manipueira sobre Meloidogyne incognita em ensaios in vitro e em tomateiros em casa de vegetação. Tropical Plant Pathology, v.35, n. 1, Jan./Fev., 2010

PELIZER, Lúcia Helena; PONTIERI, Márcia Helena; MORAES, Iracema de Oliveira; Utilização de resíduos agroindustriais em processos biotecnológicos como perspectiva de redução do impacto ambiental. Journal of Technology Management \& Innovation, v. 2, n. 1. 2007

RODRIGUEZ. N. M.; SOUSA, L. F.; CASTRO, K. Utilização de subprodutos da agroindústria na alimentação de ruminantes experiência brasileira. EV UFMG. Sem Data

ROSA, A. H.; Tese de Doutorado, Universidade Estadual Paulista, Brasil, 2001. 
ROSA, A. H.; Goveia, D.; BELLIN, I. C.; TONELLO, P. S.; ANTUNES, M. L.; DIAS FILHO, N. L.; RODRIGUES FILHO, U. P.; Química Nova. São Paulo, v. 30, n. 59, 2007.

SANTOS, André Lorena de Barros; FALEIRO, Fábio Gelape; COSTA, Ana Maria; CAMPOS, Angélica Vieira Sousa; TUPINAMBÁ, Daiva Domenech; SILVA, Karina Nascimento; FARIA, Daniela Andrade; FERNANDES, Francisco Duarte; JUQUEIRA, Nilton Tadeu Vilela; JUNQUEIRA, Keize Pereira. Caracterização de macro e micronutrientes em cascas de Passiflora edulis e Passiflora alata. IX SIMPÓSIO NACIONAL CERRADO, II SIMPÓSIO INTERNACIONAL SAVANAS TROPICAIS, Brasília, DF, 2008.

SANTOS, A.; Tese de Doutorado, Universidade de São Paulo, Brasil, 2003.

SANTOS, Max Henrique Vieira., ARAÚJO, A. C. de Araújo; SANTOS, D. M. R.; LIMA, N. da Silva; LIMA, Cícero Luiz Calazans;. Uso da manipueira como fonte de potássio na cultura da alface (Lactuca sativa L.) cultivada em casa-devegetação. Acta Scientiarum. Agronomy, Maringá, v. 32, n. 4, p. 729-733, 2010.

SODRÉ, George Andrade; VENTURINI, M. T.; RIBEIRO, D. O.; MARROCOS, P. C. L. Extrato da casca do fruto do cacaueiro como fertilizante potássico no crescimento de mudas de cacaueiro. Revista Brasileira de Fruticultura, Jaboticabal - SP, v. 34, n. 3, p. 881-887, Set., 2012.

SOUZA, Shenia Oliveira; OLIVEIRA, Luciana Camargo; CAVAGIS, Alexandre D. M.; BOTERO, Wander Gustavo. Cyanogenic Residues: Environmental Impacts, Complexation with Humic Substances, and Possible Application as Biofertilizer. Water Air Soil Pollut. n. 225, p. 2223-2236, 2014.

SOUZA, A. A.; BOIN, C. Mandioca: uma boa alternativa para substituir o milho na alimentação de bovinos de corte. Disponível em: $<$ http://www.beefpoint.com.br/bn/radar estecnicos/artigo.asp $>$

WOSIACK, G. \& CEREDA, M. P. Valorização de resíduos do processamento de mandioca. Exact and Soil Sciences, Agrarian Science and Engineering, v. 8, n.1, p. 27-43. 2002. 